\title{
A Facility-Wide Plan to Increase Access to Medication for Opioid Use Disorder in Primary Care and General Mental Health Settings
}

\author{
Juliette F. Spelman, MD; Ellen L. Edens, MD, MA, MPE; Susan Maya, MD; Brent A. Moore, PhD; Angela Boggs, PharmD; \\ Robert R. MacLean, PhD; Princess Ackland, PhD; William C. Becker, MD; Donna Lynch, MSN, CSFN, RNC; \\ Maria Garcia-Vassallo, MD; Andrea L. Burgo, MD; Marc I. Rosen, MD; and Adam J. Gordon, MD, MPH
}

\begin{abstract}
Background: The opioid epidemic in the United States has generated a pressing need to enhance access to medications for opioid use disorder (MOUD). This program description illustrates a quality-improvement effort to extend MOUD to primary care and general mental health clinics within the US Department of Veterans Affairs (VA) Connecticut Healthcare system (VACHS), and to examine barriers and facilitators to implementation of MOUD in target clinics.
\end{abstract}

Observations: As part of the national VA Stepped Care for Opioid Use Disorder Train the Trainer (SCOUTT) initiative to improve MOUD access, a VACHS team identified and resolved barriers to MOUD in target clinics. Key interventions were to obtain leadership support, increase waivered prescribers, and develop processes and tools to enhance prescribing. New initiatives included quarterly educational sessions, templated progress notes, and instant messaging for addiction specialist electronic consultations. MOUD receipt and prescriber characteristics were evaluated before and 1 year after implementation. There was a $4 \%$ increase in eligible patients receiving MOUD, from 552 (44\%) to $582(48 \%)(P=.04)$. The number of waivered prescribers increased from 67 to 131, and the number of buprenorphine prescribers increased from 35 to 52 over a 6 -month span, and the percentage of health care practitioners capable of prescribing within the electronic health record increased from $75 \%$ to $89 \%(P=.01)$.

Conclusions: An interdisciplinary team approach to identifying and overcoming barriers to MOUD target clinics expands access. Key interventions include interdisciplinary leadership engagement, proactive education and incentivization of target prescribers, removal of procedural barriers, and development of tools to facilitate and support prescribing. These concrete interventions can help inform other institutions interested in expanding MOUD access.
Author affiliations can be found at the end of the article.

Correspondence: Juliette Spelman (juliette.spelman@va.gov)

Fed Pract. 2021;38(10). Published online October 14. doi:10.12788/fp.0186 l: $\mathrm{n}$ the United States, opioid use disorder (OUD) is a major public health challenge. In 2018 drug overdose deaths were 4 times higher than they were in 1999. ${ }^{1}$ This increase highlights a critical need to expand treatment access. Medication for opioid use disorder (MOUD), including methadone, naltrexone, and buprenorphine, improves outcomes for patients retained in care. ${ }^{2}$ Compared with the general population, veterans, particularly those with co-occurring posttraumatic stress disorder (PTSD) or depression, are more likely to receive higher dosages of opioid medications and experience opioid-related adverse outcomes (eg, overdose, OUD) ${ }^{3,4}$ As a risk reduction strategy, patients receiving potentially dangerous full-dose agonist opioid medication who are unable to taper to safer dosages may be eligible to transition to buprenorphine. ${ }^{5}$

Buprenorphine and naltrexone can be prescribed in office-based settings or in addiction, primary care, mental health, and pain clinics. Office-based opioid treatment with buprenorphine (OBOT-B) expands access to patients who are not reached by addiction treatment programs. ${ }^{6,7}$ This is particularly true in rural settings, where addiction care services are typically scarce. ${ }^{8}$ OBOT-B prevents relapse and maintains opioid-free days and may increase patient engagement by reducing stigma and providing treatment within an existing clinical care team. ${ }^{9}$ For many patients, OBOT-B results in good retention with just medical monitoring and minimal or no ancillary addiction counseling. ${ }^{10,11}$

Successful implementation of OBOT-B has occurred through a variety of care models in selected community health care settings. , $^{8,12,13}$ Historically in the Veterans Health Administration (VHA), MOUD has been prescribed in substance use disorder clinics by mental health practitioners. Currently, more than $44 \%$ of veterans with OUD are on MOUD. ${ }^{14}$

The VHA has invested significant resources to improve access to MOUD. In 2018, the Stepped Care for Opioid Use Disorder Train the Trainer (SCOUTT) initiative launched, with the aim to improve access within primary care, mental health, and pain clinics. ${ }^{15}$ SCOUTT emphasizes stepped-care treatment, with patients engaging in the step 
of care most appropriate to their needs. Step 0 is self-directed care/self-management, including mutual support groups; step-1 environments include office-based primary care, mental health, and pain clinics; and step-2 environments are specialty care settings. Through a series of remote webinars, an inperson national 2-day conference, and external facilitation, SCOUTT engaged 18 teams representing each Veterans Integrated Service Network (VISN) across the country to assist in implementing MOUD within 2 step-1 clinics. These teams have developed several models of providing step-1 care, including an interdisciplinary team-based primary care delivery model as well as a pharmacist care manager model. ${ }^{16,17}$

US Department of Veterans Affairs (VA) Connecticut Health Care System (VACHS), which delivers care to approximately 58,000 veterans, was chosen to be a phase 1 SCOUTT site. Though all patients in VACHS have access to specialty care step-2 clinics, including methadone and buprenorphine programs, there remained many patients not yet on MOUD who could benefit from it. Baseline data (fiscal year [FY] 2018 4th quarter), obtained through electronic health record (EHR) database dashboards indicated that $710(56 \%)$ patients with an OUD diagnosis were not receiving MOUD. International Classification of Disease, 10th Revision codes are the foundation for VA population management dashboards, and based their data on codes for opioid abuse and opioid dependence. These tools are limited by the accuracy of coding in EHRs. Additionally, 366 patients receiving long-term opioid prescriptions were identified as moderate, high, or very high risk for overdose or death based on an algorithm that considered prescribed medications, sociodemographics, and comorbid conditions, as characterized in the VA EHR (Stratification Tool for Opioid Risk Mitigation [STORM] report). ${ }^{18}$

This article describes the VACHS quality-improvement effort to extend OBOT$B$ into step-1 primary care and general mental health clinics. Our objectives are to (1) outline the process for initiating SCOUTT within VACHS; (2) examine barriers to implementation and the SCOUTT team response; (3) review VACHS patient and prescriber data at baseline and 1 year after implementation; and (4) explore future implementation strategies.

\section{SCOUTT TEAM}

A VACHS interdisciplinary team was formed and attended the national SCOUTT kickoff conference in 2018. ${ }^{15}$ Similar to other SCOUTT teams, the team consisted of VISN leadership (in primary care, mental health, and addiction care), pharmacists, and a team of health care practitioners (HCPs) from step-2 clinics (including 2 addiction psychiatrists, and an advanced practice registered nurse, a registered nurse specializing in addiction care), and a team of HCPs from prospective step-1 clinics (including a clinical psychologist and 2 primary care physicians). An external facilitator was provided from outside the VISN who met remotely with the team to assist in facilitation. Our team met monthly, with the goal to identify local barriers and facilitators to OBOT-B and implement interventions to enhance prescribing in step- 1 primary care and general mental health clinics.

\section{Implementation Steps}

The team identified multiple barriers to dissemination of OBOT-B in target clinics (Table). The 3 main barriers were limited leadership engagement in promoting OBOT$\mathrm{B}$ in target clinics, inadequate number of $\mathrm{HCPs}$ with active $\mathrm{X}$-waivered prescribing status in the targeted clinics, and the need for standardized processes and tools to facilitate prescribing and follow-up.

To address leadership engagement, the SCOUTT team held quarterly presentations of SCOUTT goals and progress on target clinic leadership calls (usually 15 minutes) and arranged a 90-minute multidisciplinary leadership summit with key leadership representation from primary care, general mental health, specialty addiction care, nursing, and pharmacy. To enhance $\mathrm{X}$-waivered prescribers in target clinics, the SCOUTT team sent quarterly emails with brief education points on MOUD and links to waiver trainings. At the time of implementation, in order to prescribe buprenorphine and meet qualifications to treat OUD, prescribers were required to complete specialized training as necessitated by the Drug Addiction Treatment Act of 2000. 
X-waivered status can now be obtained without requiring training

The SCOUTT team advocated for Xwaivered status to be incentivized by performance pay for primary care practitioners and held quarterly case-based education sessions during preexisting allotted time. The onboarding process for new waivered prescribers to navigate from waiver training to active prescribing within the EHR was standardized via development of a standard operating procedure (SOP).

The SCOUTT team also assisted in the development of standardized processes and tools for prescribing in target clinics, including implementation of a standard operating procedure regarding prescribing (both initiation of buprenorphine, and maintenance) in target clinics. This procedure specifies that target clinic HCPs prescribe for patients requiring less intensive management, and who are appropriate for office-based treatment based on specific criteria (eAppendix, available at doi:10.12788/fp.0186).

Templated progress notes were created for buprenorphine initiation and buprenorphine maintenance with links to recommended laboratory tests and urine toxicology test ordering, home induction guides, prescription drug monitoring database, naloxone prescribing, and pharmacy order sets. Communication with specialty HCPs was facilitated by development of e-consultation within the EHR and instant messaging options within the local intranet. In the SCOUTT team model, the prescriber independently completed assessment/follow-up without nursing or clinical pharmacy support.

\section{Analysis}

We examined changes in MOUD receipt and prescriber characteristics at baseline (FY 2018 4th quarter) and 1 year after implementation (FY 2019 4th quarter). Patient data were extracted from the VHA Corporate Data Warehouse (CDW), which contains data from all VHA EHRs. The VA STORM, is a CDW tool that automatically flags patients prescribed opioids who are at risk for overdose and suicide. Prescriber data were obtained from the Buprenorphine/XWaivered Provider Report, a VA Academic Detailing Service database that provides details on HCP type, $\mathrm{X}$-waivered status, and prescribing by location. $\chi^{2}$ analyses were conducted on before and after measures when total values were available.

\section{RESULTS}

There was a $4 \%$ increase in patients with an OUD diagnosis receiving MOUD, from $552(44 \%)$ to $582(48 \%)(P=.04)$, over this time. The number of waivered prescribers increased from 67 to 131, the number of prescribers of buprenorphine in a 6-month span increased from 35 to 52, and the percentage of HCPs capable of prescribing within the EHR increased from $75 \%$ to $89 \%(P=.01)$.

Initially, addiction HCPs prescribed to about $68 \%$ of patients on buprenorphine, with target clinic HCPs prescribing to $24 \%$ (with the remaining coming from other specialty HCPs). On follow-up, addiction professionals prescribed to $63 \%$, with target clinic clincians prescribing to $32 \%$.

\section{Interpretation}

SCOUTT team interventions succeeded in increasing the number of patients receiving MOUD, a substantial increase in waivered HCPs, an increase in the number of waivered HCPs prescribing MOUD, and an increase in the proportion of patients receiving MOUD in step-1 target clinics. It is important to note that within the quality-improvement framework and goals of our SCOUTT team that the data were not collected as part of a research study but to assess impact of our interventions. Within this framework, it is not possible to directly attribute the increase in eligible patients receiving MOUD solely to SCOUTT team interventions, as other factors may have contributed, including improved awareness of HCPs.

\section{SUMMARY AND FUTURE DIRECTIONS}

Since implementation of SCOUTT in August 2018, VACHS has identified several barriers to buprenorphine prescribing in step- 1 clinics and implemented strategies to overcome them. Describing our approach will hopefully inform other large health care systems (VA or non-VA) on changes required in order to scale up implementation of OBOT-B. The VACHS SCOUTT team was successful at enhancing a ready workforce in step-1 clinics, though noted a delay in changing prescribing practice and culture. 
TABLE Barriers and Resolutions to implementation of OBOT-B in VACHS Clinics

\begin{tabular}{|c|c|}
\hline Barriers & Approaches \\
\hline $\begin{array}{l}\text { Limited leadership engagement } \\
\text { in promoting OBOT-B }\end{array}$ & $\begin{array}{l}\text { - Incorporated quarterly progress reports into regional primary care leadership call } \\
\text {-90-minute leadership summit with primary care, mental health care, SUD care, nursing, and } \\
\text { pharmacy leadership } \\
\text { 1-day in-person SUD regional leadership meeting }\end{array}$ \\
\hline Clinicians without $X$-waivers & $\begin{array}{l}\text { - Quarterly emails to target clinic clinicians } \\
\text { - Training courses included: } 8 \mathrm{~h} \text { online (learning.pcssnow.org); } 4 \mathrm{~h} \text { webinar and 4-h online } \\
\text { self-study } \\
\text { - X-licensure status linked to incentives for primary care; X-waiver/opioid safety components } \\
\text { qualified for } \$ 3000 \text { incentive for } 2019\end{array}$ \\
\hline $\begin{array}{l}\text { Procedural barrier for waivered } \\
\text { prescribers }\end{array}$ & $\begin{array}{l}\text { - SOP onboarding for new waivered prescribers } \\
\text { - SOP generated and accepted by stakeholders }\end{array}$ \\
\hline $\begin{array}{l}\text { SOP to ensure adherence with } \\
\text { evidence-based practice within } \\
\text { target clinics }\end{array}$ & $\begin{array}{l}\text { - Created and solicited stakeholders support for SOP for waivered prescribers in clinics to } \\
\text { prescribe buprenorphine } \\
\text { - Templated buprenorphine induction and maintenance progress notes; active links to urine } \\
\text { toxicology and pharmacy order sets, home induction guides, informed consent, prescription } \\
\text { drug monitoring website, and naloxone prescription }\end{array}$ \\
\hline $\begin{array}{l}\text { Unstructured support for clinicians } \\
\text { in step-1 clinics }\end{array}$ & $\begin{array}{l}\text { - SUD e-consult for potential OBOT-B problems } \\
\text { - Instant messaging group for addiction care team }\end{array}$ \\
\hline $\begin{array}{l}\text { Understaffed clinics unable to } \\
\text { accommodate buprenorphine prescribing }\end{array}$ & - Telebuprenorphine clinics at outpatient clinics \\
\hline
\end{tabular}

Abbreviations: OBOT-B, office-based opioid treatment with buprenorphine; SOP, standard operating procedure; SUD, substance use disorder; VACHS, Veterans Affairs Connecticut Healthcare System.

We recommend utilizing academic detailing to work with clinics and individual HCPs to identify and overcome barriers to prescribing. Also, we recommend implementation of a nursing or clinical pharmacy collaborative care model in target step-1 clinics (rather than the HCP-driven model). A collaborative care model reflects the patient aligned care team (PACT) principle of team-based efficient care, and PACT nurses or clinical pharmacists should be able to provide the minimal quarterly follow-up of clinically stable patients on MOUD within the step-1 clinics. Templated notes for assessment, initiation, and followup of patients on MOUD are now available from the SCOUTT national program and should be broadly implemented to facilitate adoption of the collaborative model in target clinics. In order to accomplish a full collaborative model, the VHA would need to enhance appropriate staffing to support this model, broaden access to telehealth, and expand incentives to teams/clinicians who prescribe in these settings.

\section{Acknowledgments/Funding}

This material is based upon work supported by the US Department of Veterans Affairs (VA), Office of Mental Health and
Suicide Prevention, Veterans Health Administration; the VA Health Services Research and Development (HSR\&D) Quality Enhancement Research Initiative (QUERI) Partnered Evaluation Initiative (PEC) grants \#19-001. Supporting organizations had no further role in the study design; in the collection, analysis and interpretation of data; in the writing of the report; or in the decision to submit the paper for publication.

\section{Author affiliations}

Juliette Spelman is a Primary Care Physician; Ellen Edens is an Addiction Psychiatrist and Substance Use Disorder Director, National TeleMental Health Center; Brent Moore is a Research Psychologist; Angela Boggs is a Clinical Pharmacy Specialist in mental health (Clinical Resource Hub, Veterans Integrated Service Network 1); Robert MacLean is a Clinical Psychologist; William Becker is a General Internist; Donna Lynch is a Clinical Nurse Coordinator Outpatient Addiction; Maria GarciaVassallo is an Addiction Psychiatrist; Andrea Burgo is a Primary Care Physician and National Co-Director for the Veterans Health Administration Primary Care Pain Initiative and Post Deployment Integrated Care Initiative; Marc Rosen is an Addiction Psychiatrist and Director of Addiction Treatment programs; all at Veterans Affairs Connecticut Health Care System, in West Haven. Susan Maya is a Primary Care Physician at Beth Israel Deaconess Medical Center and an Instructor in Medicine at Harvard Medical School in Boston, Massachusetts. Princess Ackland is an Investigator and Staff Psychologist at Center for Care Delivery and Outcomes Research, Minneapolis Veterans Affairs Health Care System and an Assistant Professor of Medicine at the University of Minnesota School of Medicine. Adam Gordon is a Physician, Chief of Addiction Medicine, and Core Faculty at Informatics, Decision-Enhancement, and Analytic Sciences Center, Veterans Affairs Salt Lake City Health Care System and a Professor of Medicine and Psychiatry and Director of the Program for Addiction Research, Clinical Care, Knowledge and Advocacy, Division of Epidemiology, Department 
of Internal Medicine, University of Utah School of Medicine in Salt Lake City. Marc Rosen is a Professor of Psychiatry; Andrea Burgo is an Assistant Clinical Professor of Medicine; Maria Garcia-Vassallo is an Assistant Professor of Psychiatry; William Becker is an Associate Professor of Medicine; Robert MacLean is an Assistant Professor of Psychiatry; Ellen Edens is an Associate Professor of Psychiatry; Juliette Spelman is an Assistant Professor of Medicine; Brent Moore is a Research Scientist; all at Yale School of Medicine in New Haven.

\section{Author disclosures}

The authors report no actual or potential conflicts of interest with regard to this article.

\section{Disclaimer}

The opinions expressed herein are those of the authors and do not necessarily reflect those of Federal Practitioner, Frontline Medical Communications Inc., the US Government, or any of its agencies. This article may discuss unlabeled or investigational use of certain drugs. Please review the complete prescribing information for specific drugs or drug combinations -including indications, contraindications, warnings, and adverse effects-before administering pharmacologic therapy to patients.

\section{References}

1. Centers for Disease Control and Prevention. Understanding the epidemic. Updated March 17, 2021. Accessed September 17, 2021. https://www.cdc.gov/drugoverdose /epidemic/index.html

2. Blanco C, Volkow ND. Management of opioid use disorder in the USA: present status and future directions. Lancet. 2019;393(10182):1760-1772. doi:10.1016/S0140-6736(18)33078-2

3. Seal KH, Shi Y, Cohen G, et al. Association of mental health disorders with prescription opioids and high risk opioid use in US veterans of Iraq and Afghanistan [published correction appears in JAMA. 2012 Jun 20;307(23):2489]. JAMA. 2012;307(9):940-947. doi:10.1001/jama.2012.234

4. Bohnert AS, Ilgen MA, Trafton JA, et al. Trends and regional variation in opioid overdose mortal ity among Veterans Health Administration patients, fiscal year 2001 to 2009. Clin J Pain. 2014;30(7):605-612. doi:10.1097/AJP.0000000000000011

5. US Department of Health and Human Services, Working Group on Patient-Centered Reduction or Discontinuation of Long-term Opioid Analgesics. HHS guide for clinicians on the appropriate dosage reduction or discontinuation of Long-term opioid analgesics. Published October 2019. Accessed September 17, 2021. https://www.hhs.gov /opioids/sites/default/files/2019-10/Dosage_Reduction _Discontinuation.pdf

6. Sullivan LE, Chawarski M, O'Connor PG, Schottenfeld RS, Fiellin DA. The practice of office-based buprenorphine treatment of opioid dependence: is it associated with new patients entering into treatment?. Drug Alcohol Depend. 2005;79(1):113-116. doi:10.1016/j.drugalcdep.2004.12.008

7. LaBelle CT, Han SC, Bergeron A, Samet JH. Office-based opioid treatment with buprenorphine (OBOT-B): statewide implementation of the Massachusetts collaborative care model in community health centers. J Subst Abuse Treat. 2016;60:6-13. doi:10.1016/j.jsat.2015.06.010

8. Rubin R. Rural veterans less likely to get medication for opioid use disorder. JAMA. 2020;323(4):300. doi:10.1001/jama.2019.21856

9. Kahan M, Srivastava A, Ordean A, Cirone S. Buprenorphine: new treatment of opioid addiction in primary care. Can Fam Physician. 2011;57(3):281-289.

10. Fiellin DA, Moore BA, Sullivan LE, et al. Long-term treatment with buprenorphine/naloxone in primary care: results at 2-5 years. Am J Addict. 2008;17(2):116-120. doi:10.1080/10550490701860971

11. Fiellin DA, Pantalon MV, Chawarski MC, et al. Counseling plus buprenorphine-naloxone maintenance therapy for opioid dependence. N Engl J Med. 2006;355(4):365-374. doi:10.1056/NEJMoa055255

12. Haddad MS, Zelenev A, Altice FL. Integrating buprenorphine maintenance therapy into federally qualified health centers: real-world substance abuse treatment outcomes. Drug Alcohol Depend. 2013;131(1-2):127-135. doi:10.1016/j.drugalcdep.2012.12.008

13. Alford DP, LaBelle CT, Richardson JM, et al. Treating homeless opioid dependent patients with buprenorphine in an office-based setting. J Gen Intern Med. 2007;22(2):171176. doi:10.1007/s11606-006-0023-1

14. Wyse JJ, Gordon AJ, Dobscha SK, et al. Medications for opioid use disorder in the Department of Veterans Affairs (VA) health care system: Historical perspective, lessons learned, and next steps. Subst Abus. 2018;39(2):139-144. doi:10.1080/08897077.2018.1452327

15. Gordon AJ, Drexler K, Hawkins EJ, et al. Stepped Care for Opioid Use Disorder Train the Trainer (SCOUTT) initiative: Expanding access to medication treatment for opioid use disorder within Veterans Health Administration facilities. Subst Abus. 2020;41(3):275-282. doi:10.1080/08897077.2020.1787299

16. Codell N, Kelley AT, Jones AL, et al. Aims, development, and early results of an interdisciplinary primary care initiative to address patient vulnerabilities. Am J Drug Alcohol Abuse. 2021;47(2):160-169. doi:10.1080/00952990.2020.1832507

17. DeRonne BM, Wong KR, Schultz E, Jones E, Krebs EE. Implementation of a pharmacist care manager model to expand availability of medications for opioid use disorder. Am J Health Syst Pharm. 2021;78(4):354-359. doi:10.1093/ajhp/zxaa405

18. Oliva EM, Bowe T, Tavakoli S, et al. Development and applications of the Veterans Health Administration's Stratification Tool for Opioid Risk Mitigation (STORM) to improve opioid safety and prevent overdose and suicide. Psychol Serv. 2017;14(1):34-49. doi:10.1037/ser0000099

19. US Department of Defense, US Department of Veterans Affairs, Opioid Therapy for Chronic Pain Work Group. VA/DoD clinical practice guideline for opioid therapy for chronic pain. Published February 2017. Accessed August 20, 2021. https://www.va.gov/HOMELESS/nchav /resources/docs/mental-health/substance-abuse/VA _DoD-CLINICAL-PRACTICE-GUIDELINE-FOR-OPIOID -THERAPY-FOR-CHRONIC-PAIN-508.pdf 